\title{
Laterally mounted azobenzenes on platforms
}

\author{
Melanie Hammerich and Rainer Herges* \\ Otto Diels-Institute for Organic Chemistry, University of Kiel, \\ Otto-Hahn-Platz 4, Kiel, D-24119, Germany
}

\section{Table of contents}

I. $\quad{ }^{1} \mathrm{H}$ and ${ }^{13} \mathrm{C}$ NMR of compounds

Spectra of 1-[(3-Iodophenyl)methoxy]-4-nitrobenzene (4) 1

Spectra of 1-\{[3-(Trimethylsilylethinyl)phenyl]methoxy\}-4-nitrobenzene (5) 2

Spectra of 4-(3-Trimethylsilylethinylbenzyloxy)phenylamine (6) 3

Spectra of 1,2-Bis\{4-[(3-trimethylsilylbenzyloxy)phenyl]\}-diazene (7) 4

Spectra of 1,2-Bis-(4-\{[3-(4,8,12-tris-n-propyl-4,8,12-triazatriangulenium

-benzyloxy]-12c-ethinyl)phenyl\})diazene (9a) 5

Spectra of 1,2-Bis-(4-\{[3-(4,8,12-tris-n-octyl-4,8,12-triazatriangulenium-

benzyloxy]-12c-ethinyl)phenyl\})-diazene (9b) 6

II. $\quad{ }^{1} \mathrm{H}$ and ${ }^{13} \mathrm{C}$ NMR of compound $9 \mathrm{a}$ and $9 \mathrm{~b}$ after irradiation

${ }^{1} \mathrm{H}$ NMR spectra of compound 9a after irradiation $\quad$ 7-8

${ }^{1} \mathrm{H}$ NMR spectra of compound $\mathbf{9 b}$ after irradiation $\quad 9-10$

II. Half-lives of compounds $9 a$ and $9 b$

Half-life of compound 9a $\quad 11$

Half-life of compound 9b $\quad 12$

$\begin{array}{ll}\text { III. UV spectrum of compound 9a } & 13\end{array}$

$\begin{array}{ll}\text { IV. Photostability of compounds 9a and 9b } & 14\end{array}$ 
I. ${ }^{1} \mathrm{H}$ and ${ }^{13} \mathrm{C}$ NMR of compounds

\section{Spectra of 1-[(3-Iodophenyl)methoxy]-4-nitrobenzene (4)}

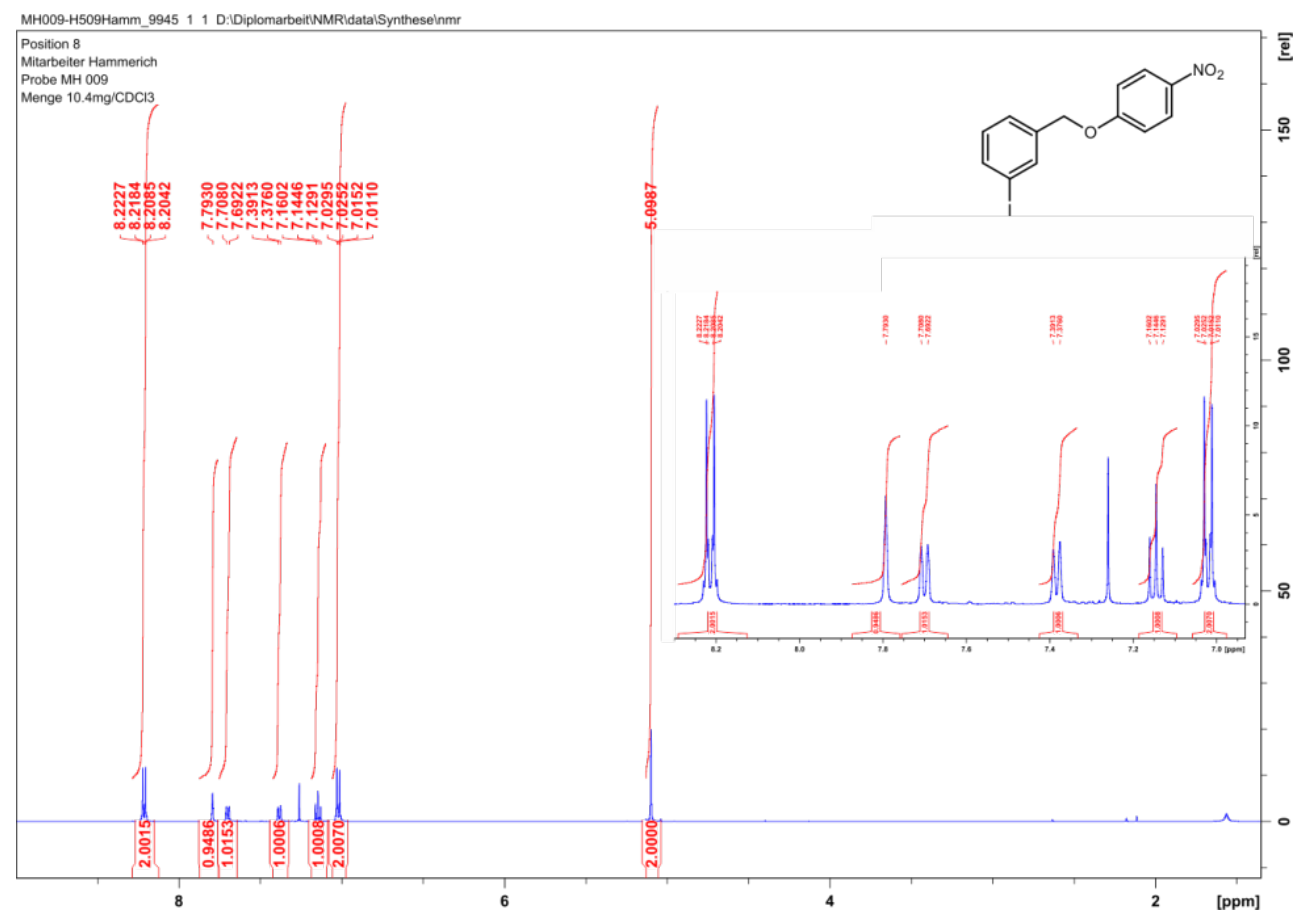

Figure S1 ${ }^{1} \mathrm{H}$ NMR of compound 4

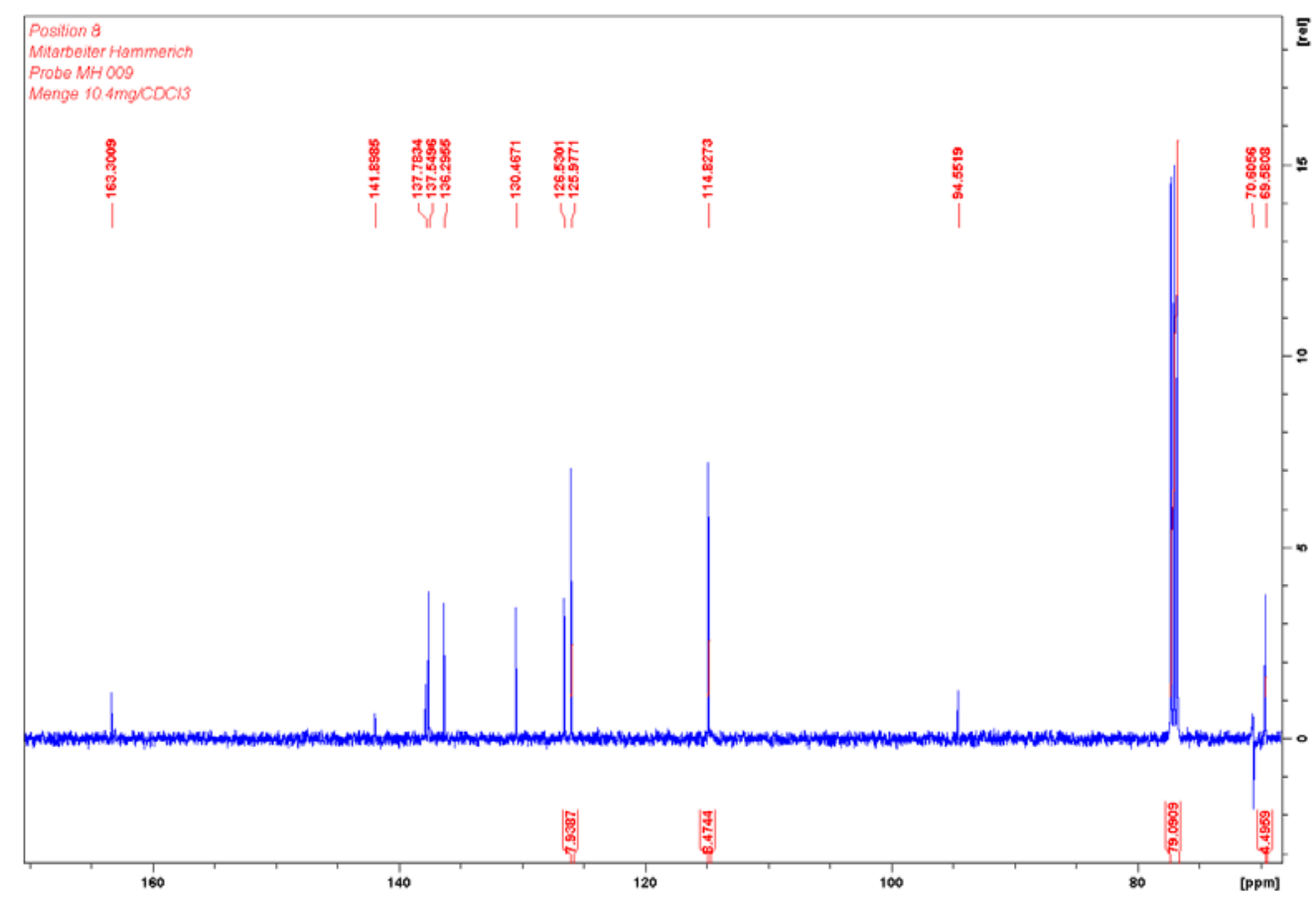

Figure S2 ${ }^{13} \mathrm{C}$ NMR of compound 4 


\section{Spectra of 1-\{[3-(Trimethylsilylethinyl)phenyl]methoxy\}-4-nitrobenzene (5)}

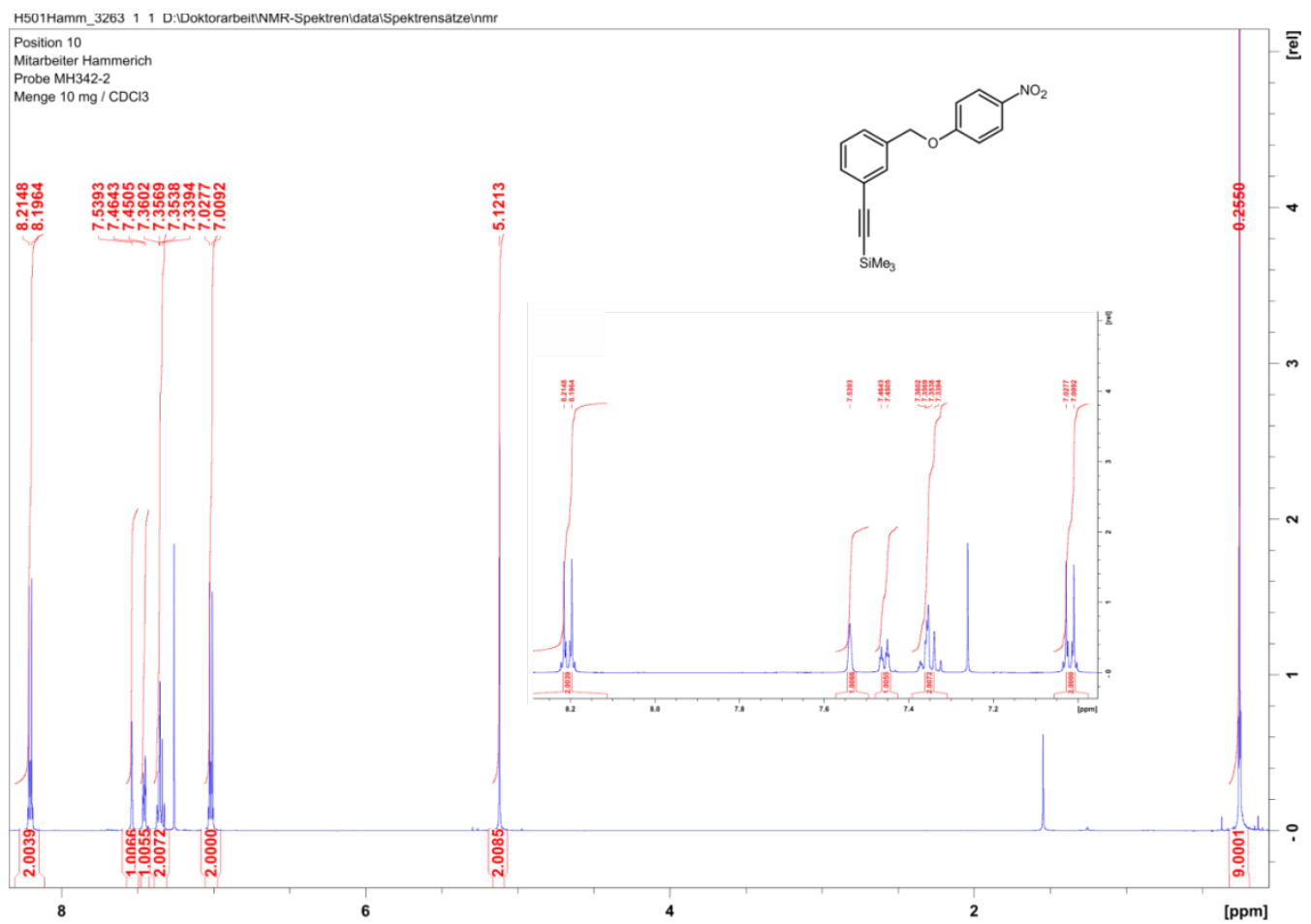

Figure S3 ${ }^{1} \mathrm{H}$ NMR of compound 5

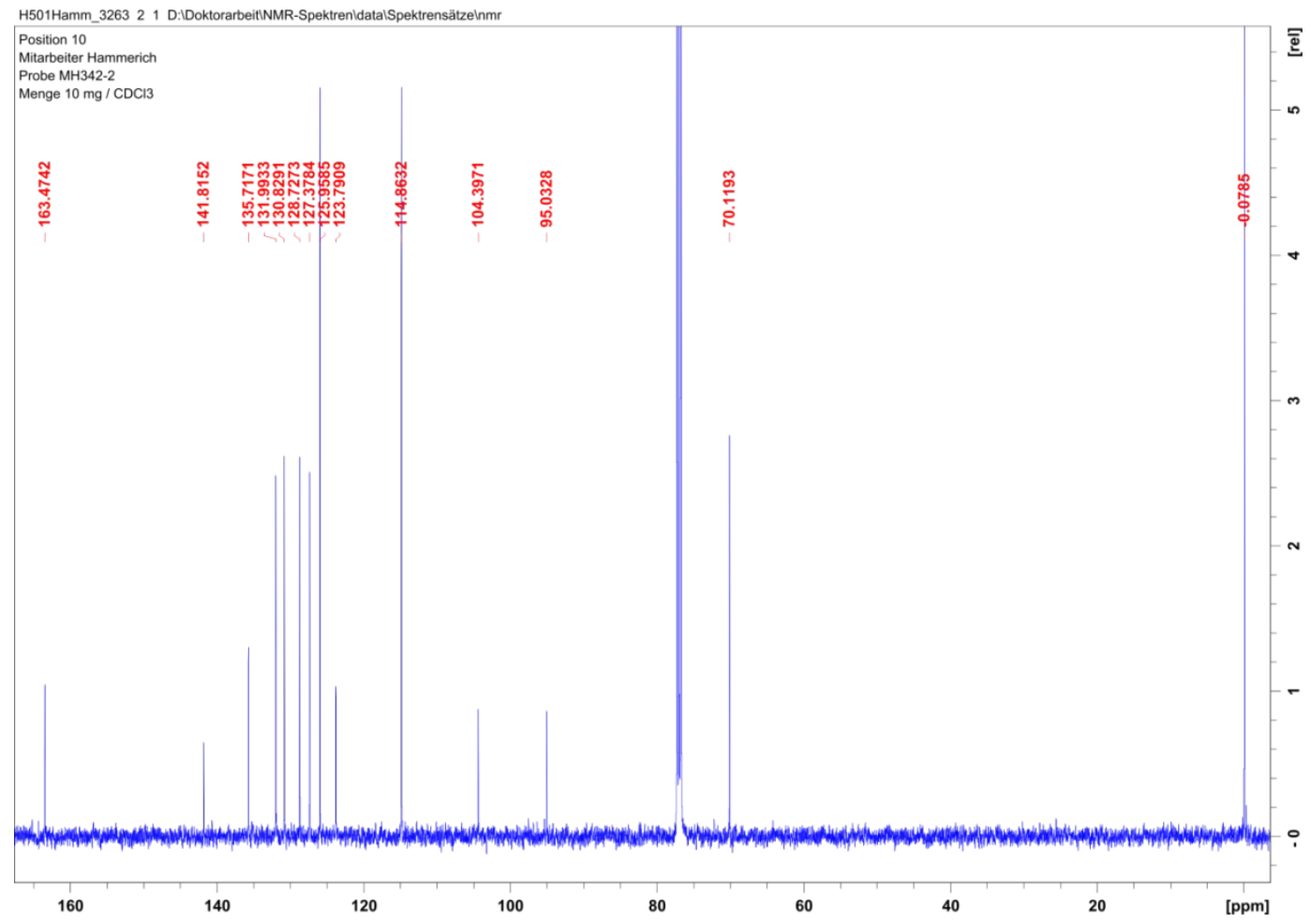

Figure $\mathrm{S} 4{ }^{13} \mathrm{C}$ NMR of compound 5 


\section{Spectra of 4-(3-Trimethylsilylethinylbenzyloxy)phenylamine (6)}

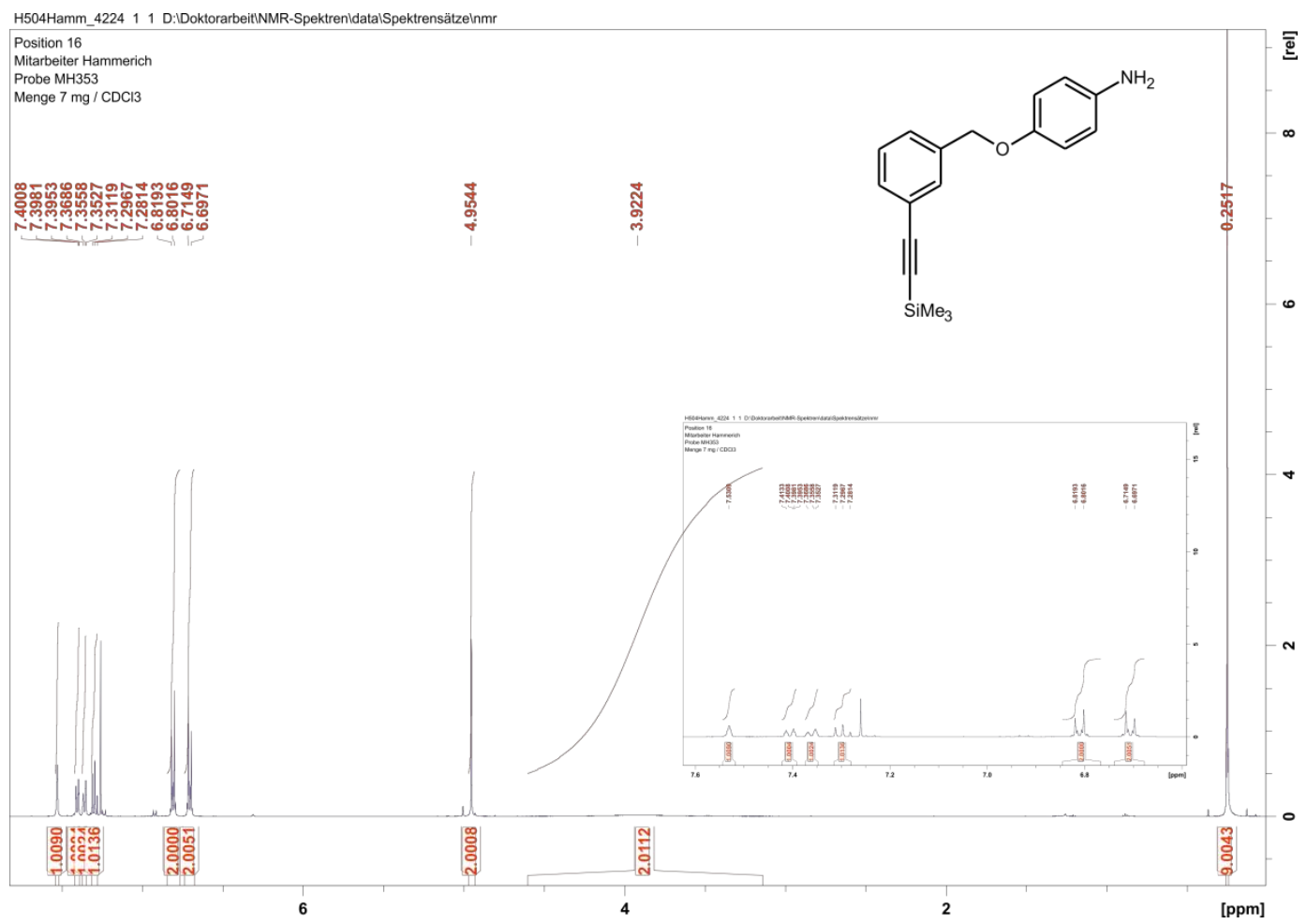

Figure S5 ${ }^{1} \mathrm{H}$ NMR of compound 6

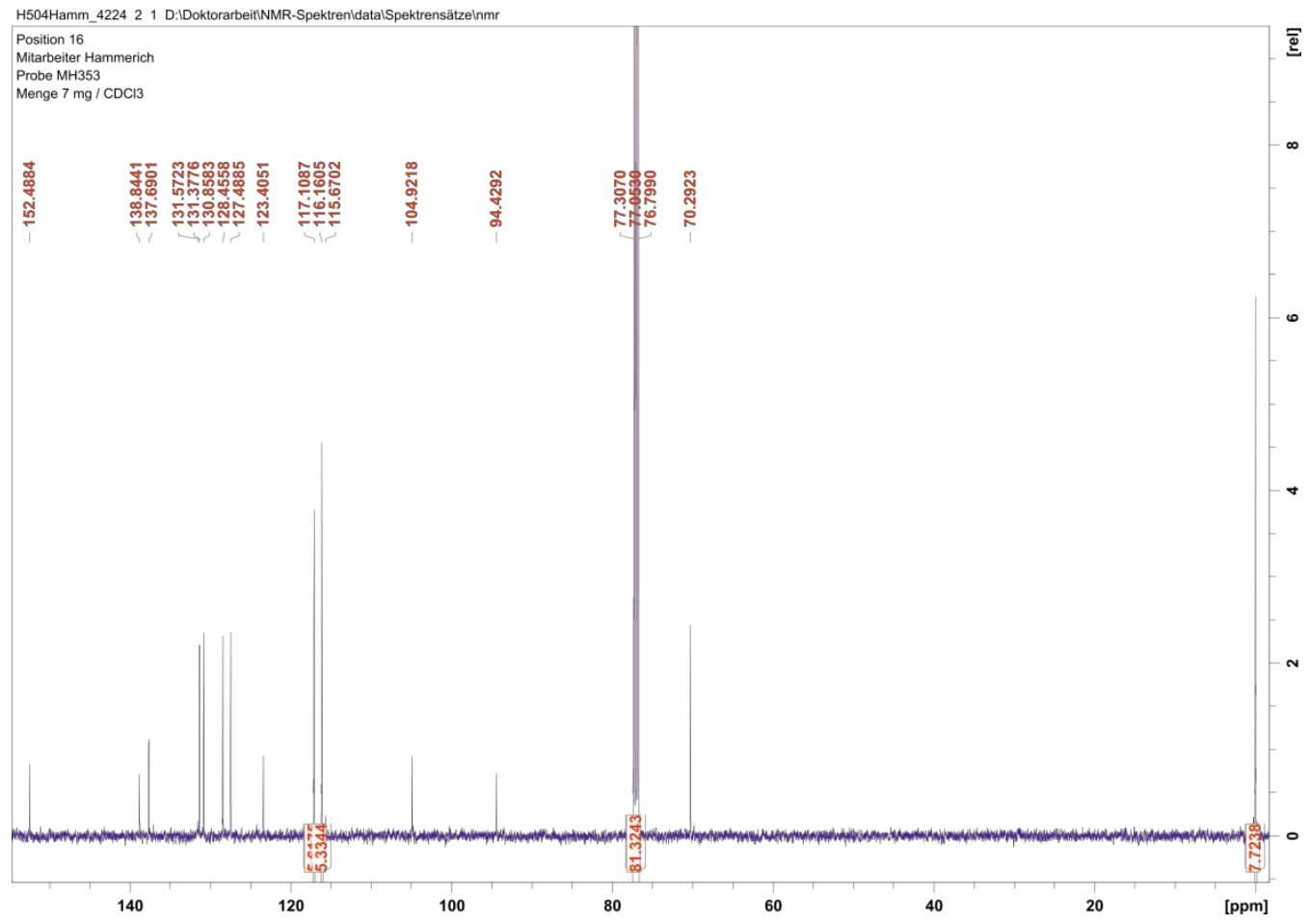

Figure S6 ${ }^{13} \mathrm{C}$ NMR of compound 6 


\section{Spectra of 1,2-Bis\{4-[(3-trimethylsilylbenzyloxy)phenyl]\}-diazene (7)}

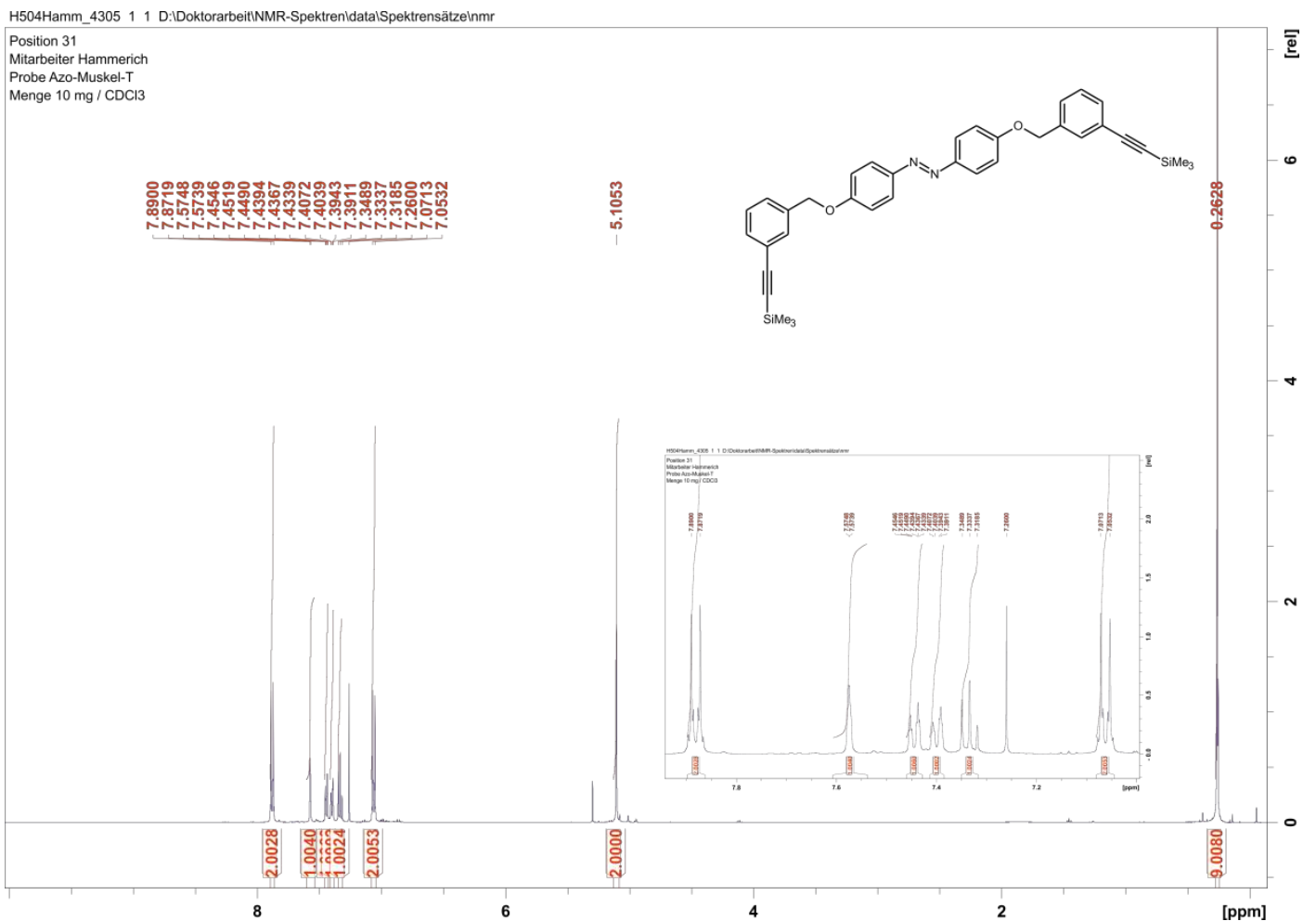

Figure S7 ${ }^{1} \mathrm{H}$ NMR of compound 7

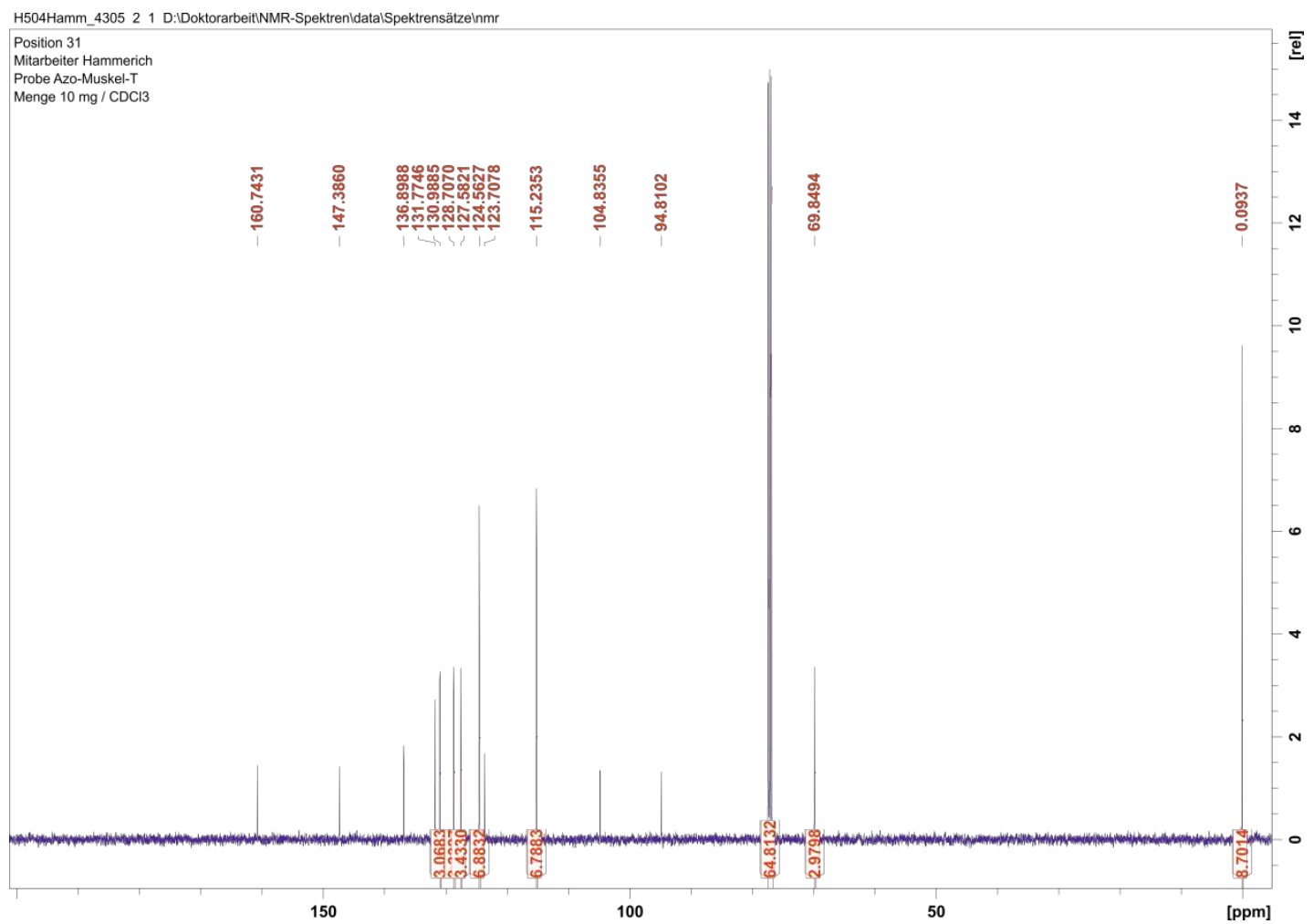

Figure S8 ${ }^{13} \mathrm{C}$ NMR of compound 7 
Spectra of 1,2-Bis-(4-\{[3-(4,8,12-tris-n-propyl-4,8,12-triazatri-anguleniumbenzyloxy]-12c-ethinyl)phenyl\})diazene (9a)

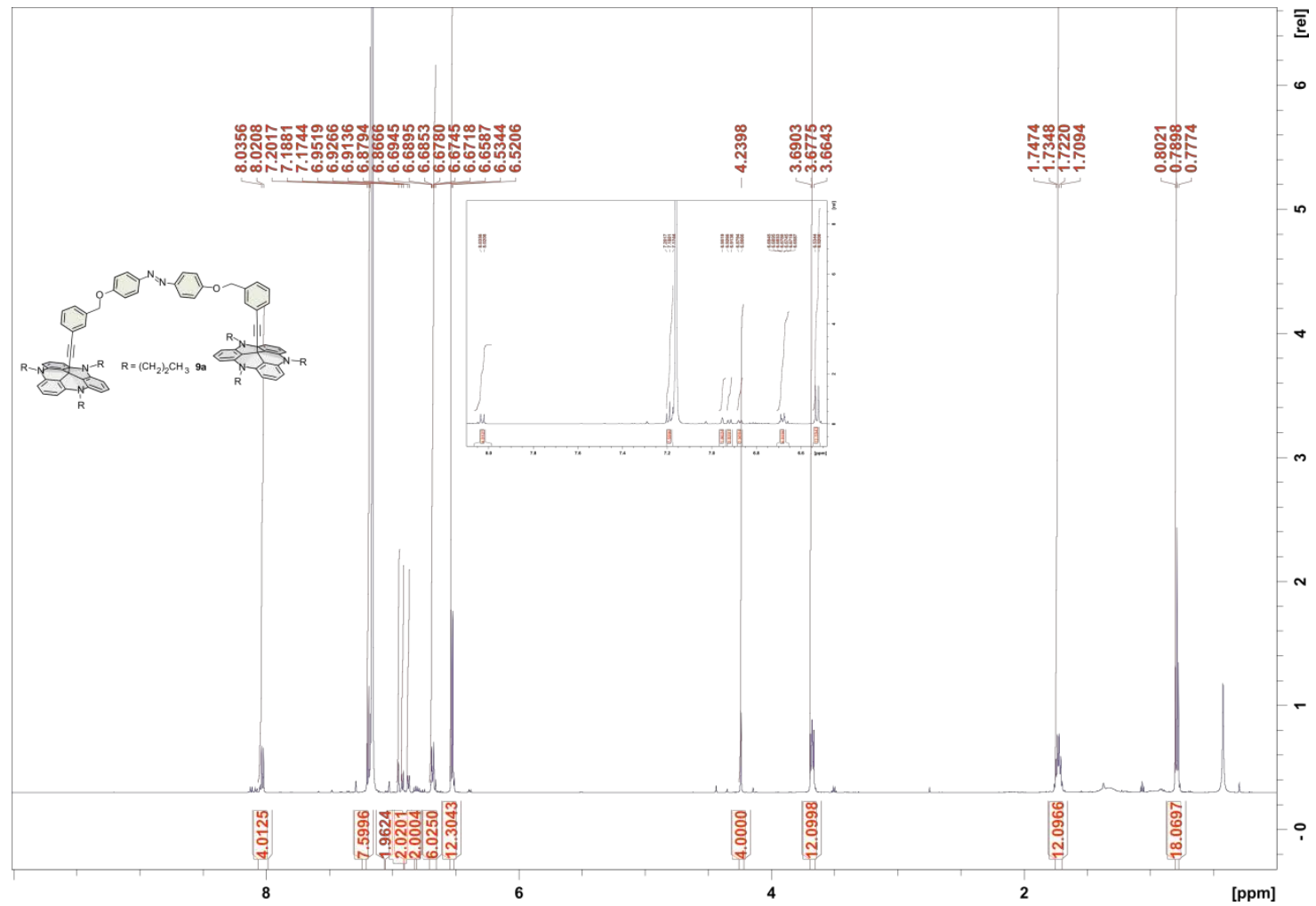

Figure S9 ${ }^{1} \mathrm{H}$ NMR of compound 9a

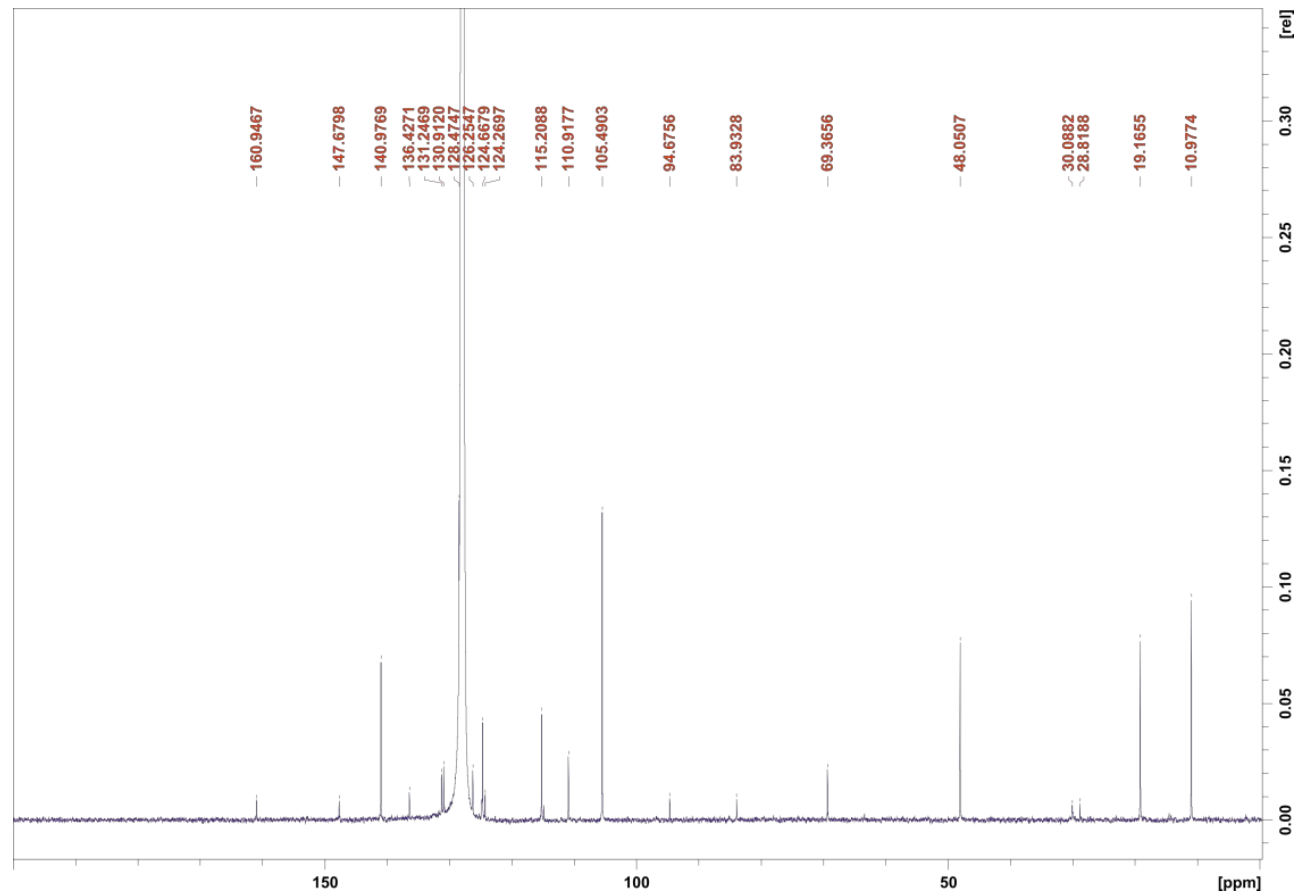

Figure S10 ${ }^{13} \mathrm{C}$ NMR of compound 9a 


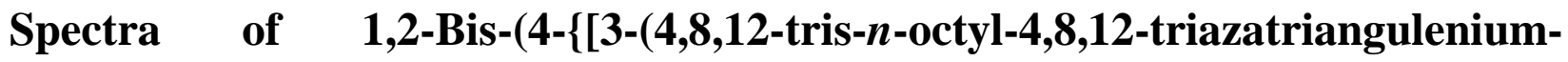
benzyloxy]-12c-ethinyl)phenyl\})-diazene (9b)

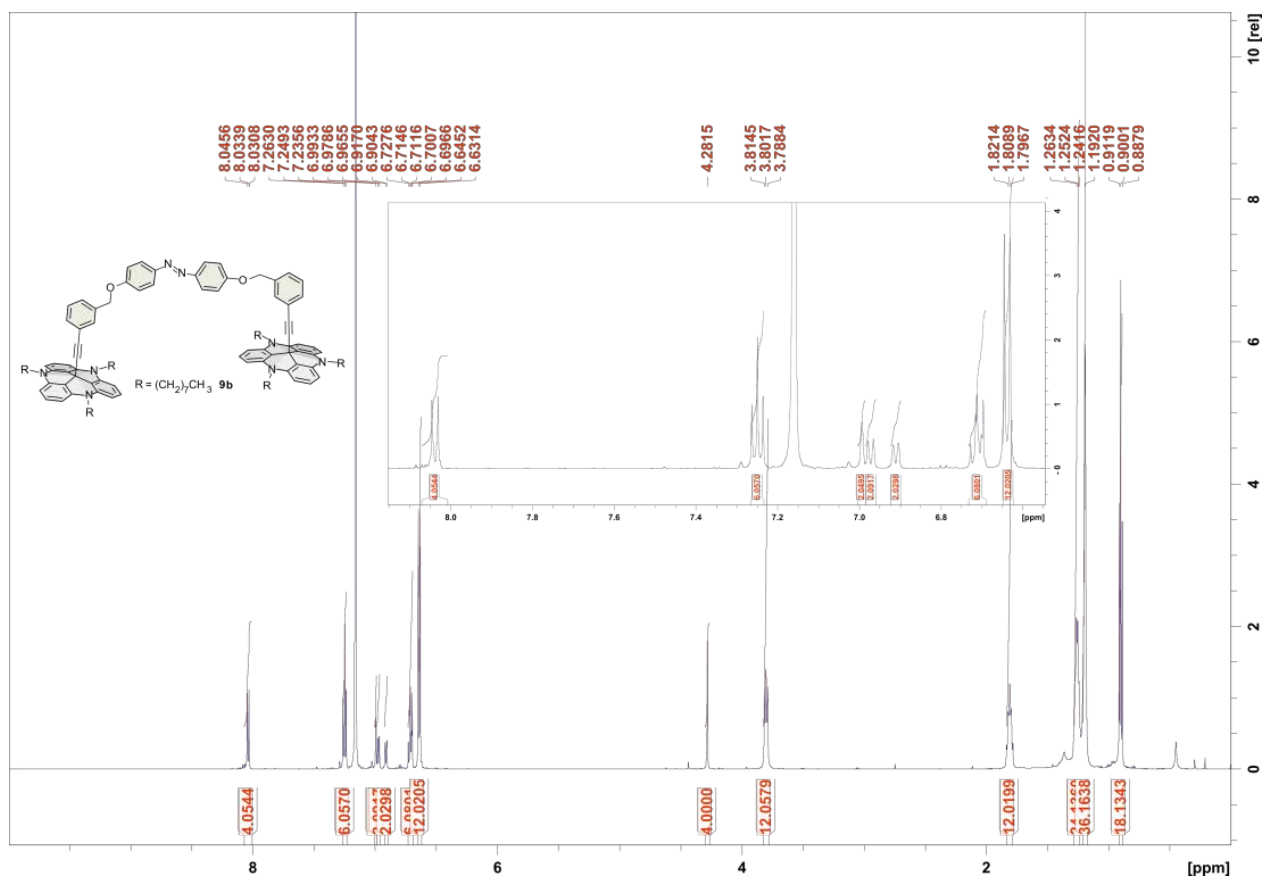

Figure S11 ${ }^{1} \mathrm{H}$ NMR of compound $9 b$

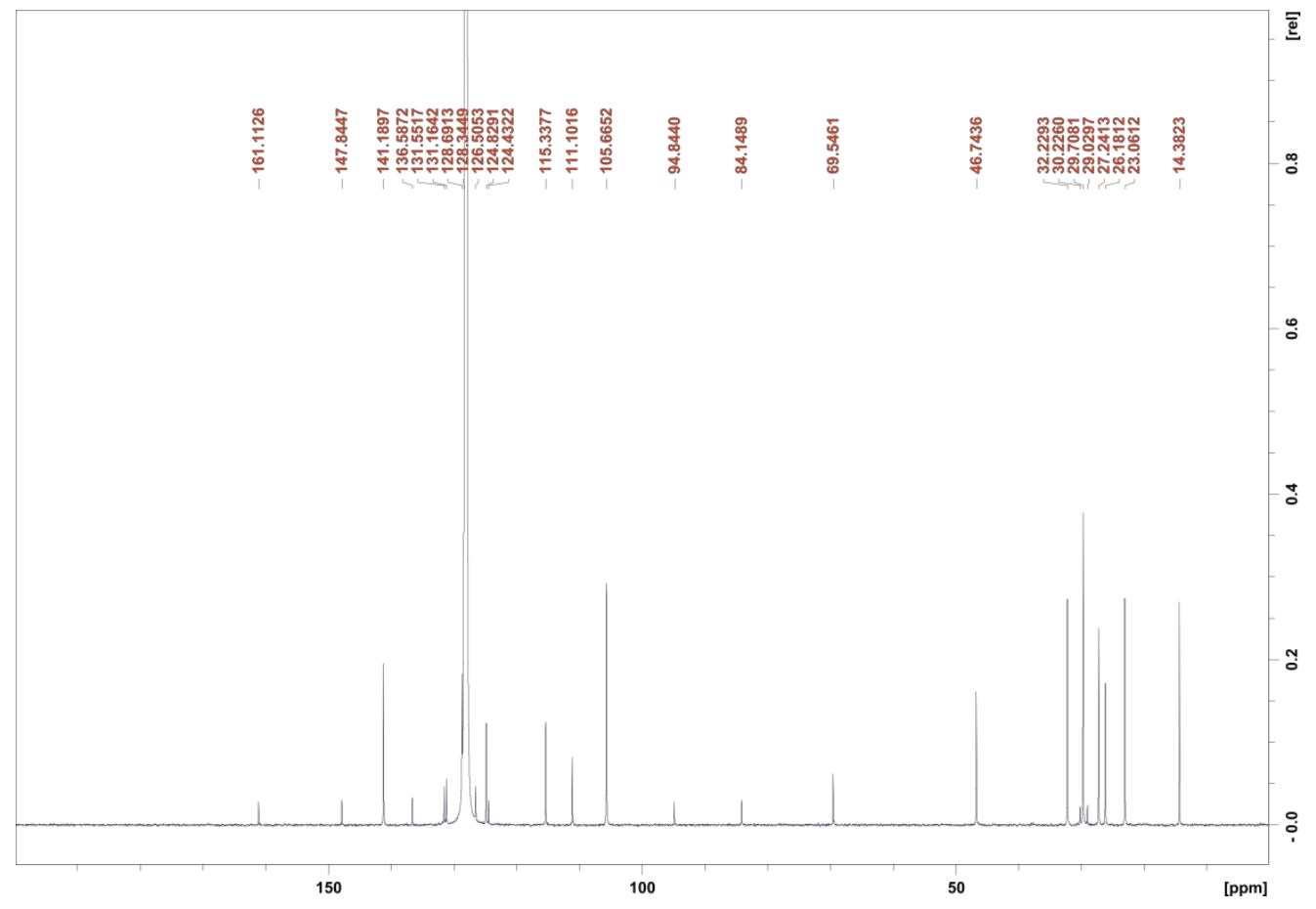

Figure $\mathbf{S 1 2}{ }^{13} \mathrm{C}$ NMR of compound $\mathbf{9 b}$ 


\section{1H and 13C NMR of compound 9a and 9b trans and cis}

The ration of cis and trans isomer were determined by ${ }^{1} \mathrm{H}$ NMR. A solution of the azobenzene was irradiated within the NMR tube with $365 \mathrm{~nm}$ (obtaining cis isomer) and $470 \mathrm{~nm}$ (obtaining trans isomer) for $10 \mathrm{~min}$ and the ratio of cis/trans were determined upon the $\mathrm{OCH}_{2}$ as this signal is well separated for both species.

II. ${ }^{1} \mathrm{H}$ NMR of compound 9a after irradiation

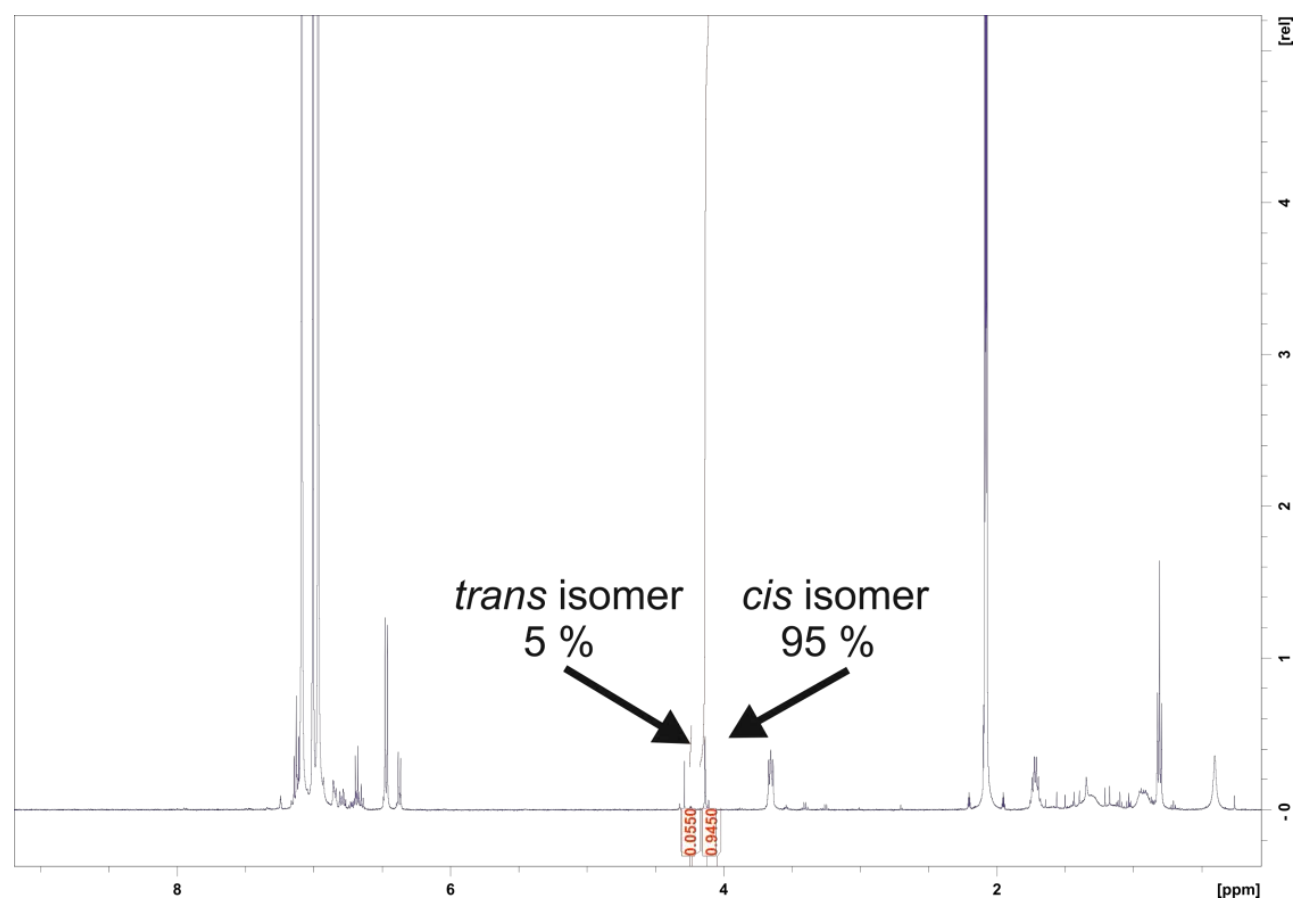

Figure S13 ${ }^{1} \mathrm{H}$ NMR of compound 9a after irradiation with $365 \mathrm{~nm}$ for $10 \mathrm{~min}$. 


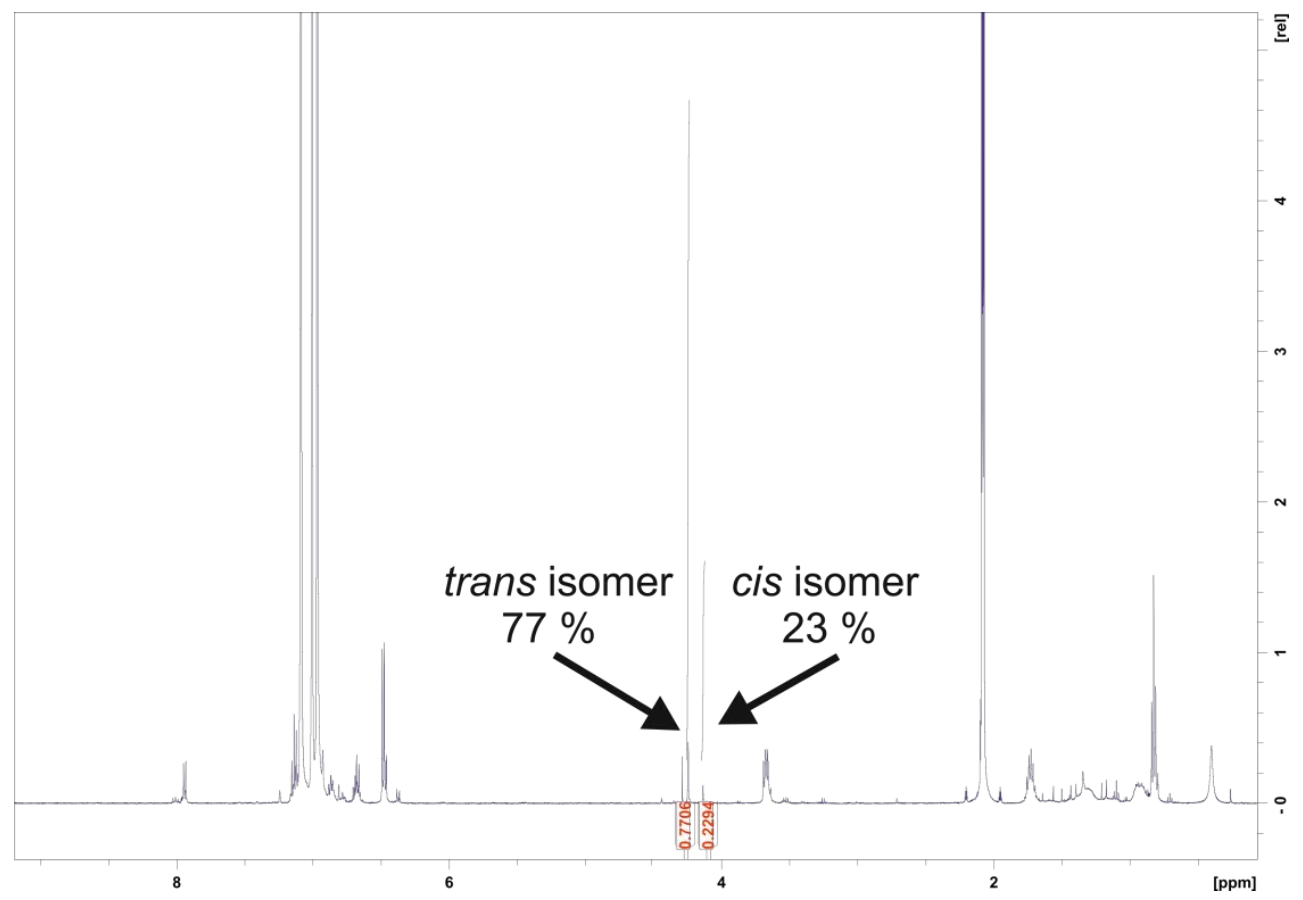

Figure S14 ${ }^{1} \mathrm{H}$ NMR of compound 9a after irradiation with $470 \mathrm{~nm}$ for $10 \mathrm{~min}$.

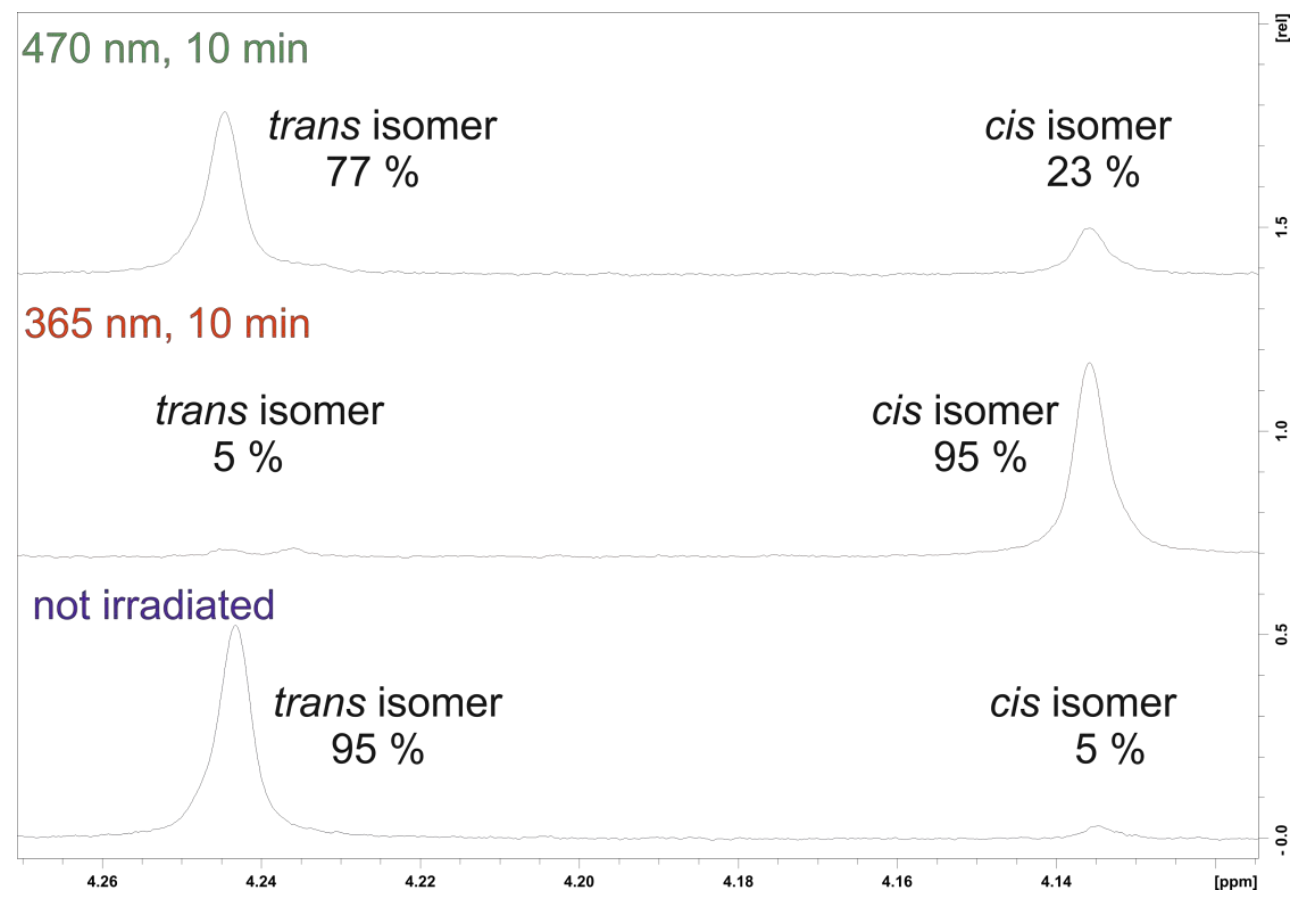

Figure S15 ${ }^{1} \mathrm{H}$ NMR of compound 9a: zoom of the $\mathrm{OCH}_{2}$ region not irradiated (blue), irradiated with $365 \mathrm{~nm}$ (red) and irradiated with $470 \mathrm{~nm}$ (green): 
II. ${ }^{1} \mathrm{H}$ NMR of compound $\mathbf{9 b}$ after irradiation

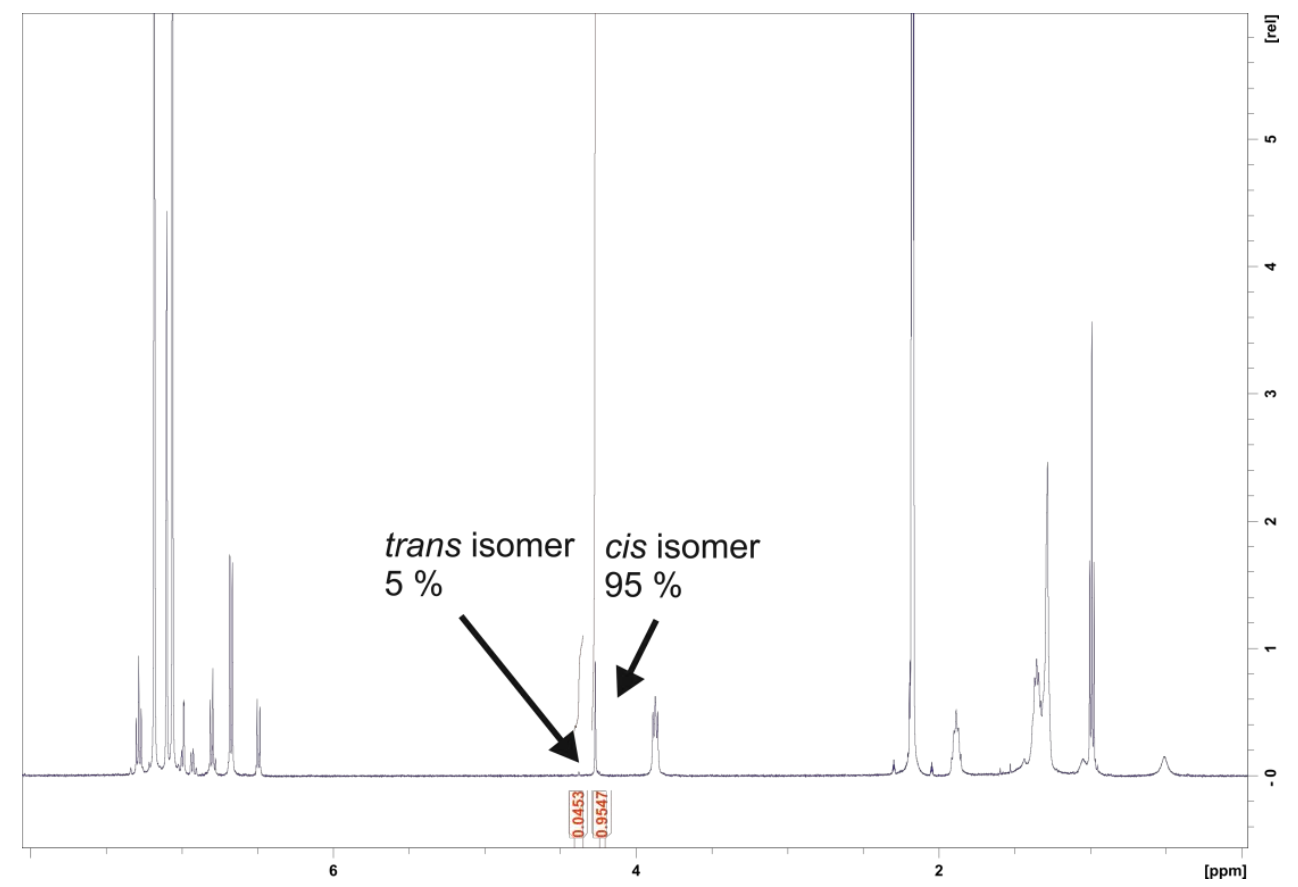

Figure S16 ${ }^{1} \mathrm{H}$ NMR of compound $\mathbf{9 b}$ after irradiation with $365 \mathrm{~nm}$ for $10 \mathrm{~min}$.

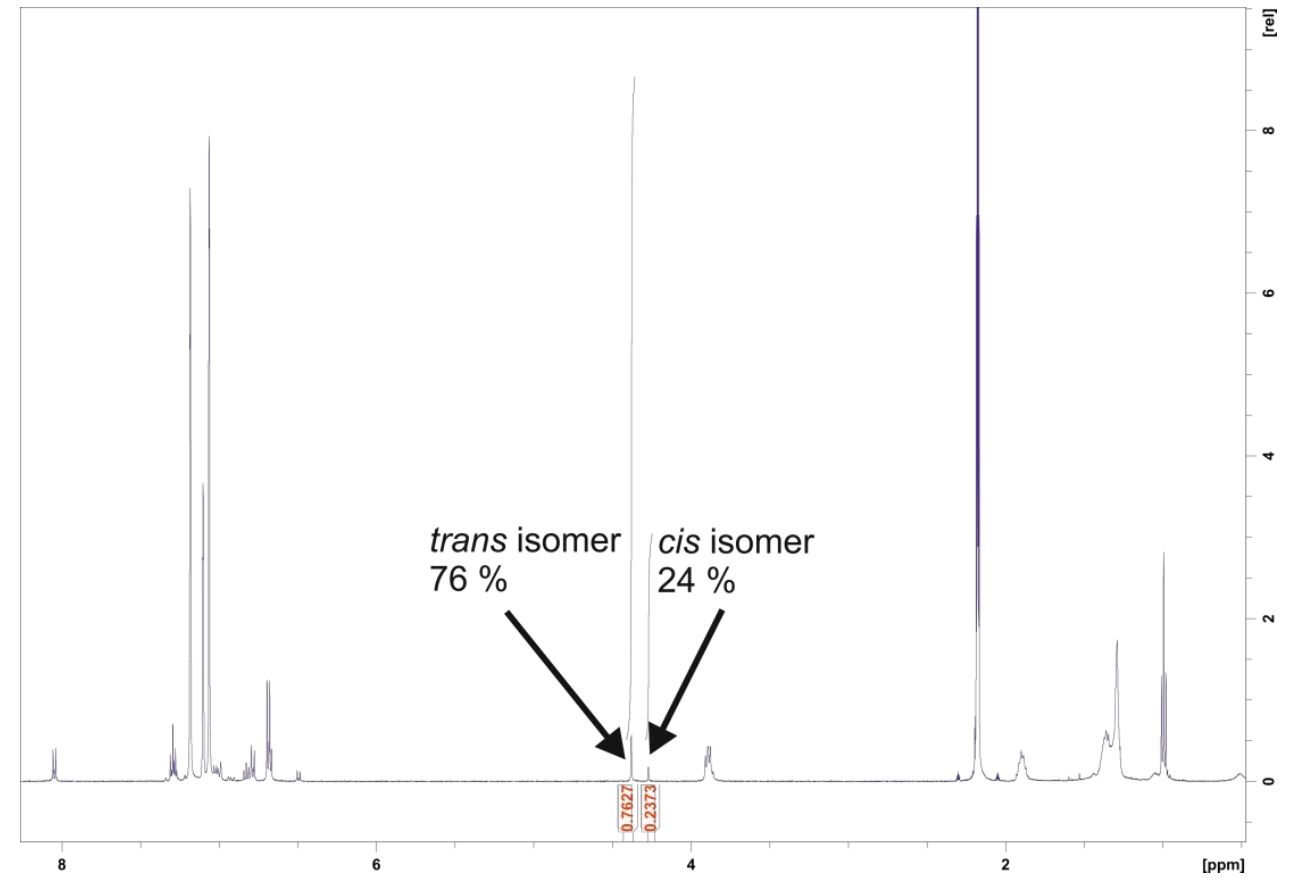

Figure S17 ${ }^{1} \mathrm{H}$ NMR of compound $9 \mathbf{b}$ after irradiation with $470 \mathrm{~nm}$ for $10 \mathrm{~min}$. 


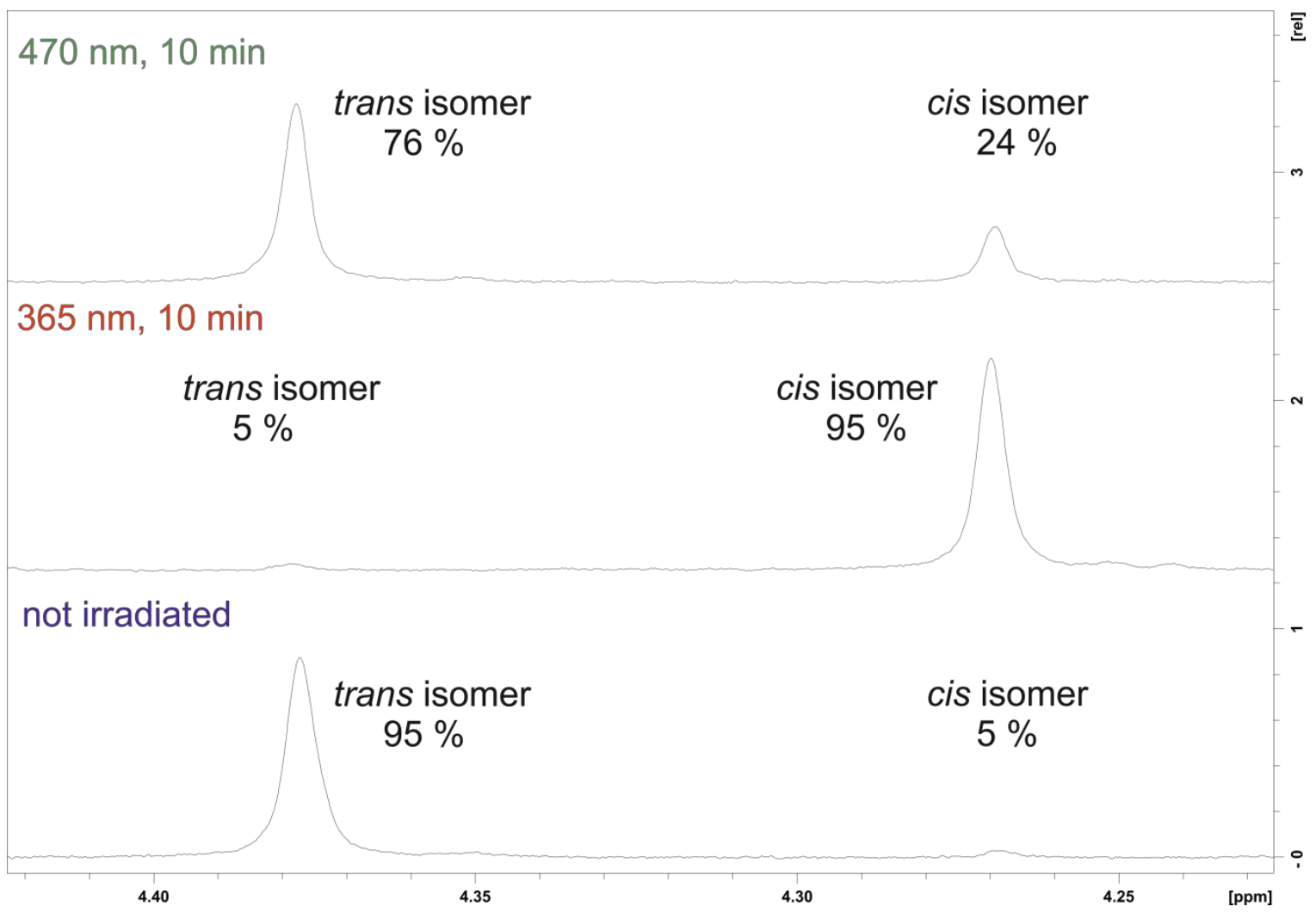

Figure S18 ${ }^{1} \mathrm{H}$ NMR of compound 9b: zoom of the $\mathrm{OCH}_{2}$ region not irradiated (blue), irradiated with $365 \mathrm{~nm}$ (red) and irradiated with $470 \mathrm{~nm}$ (green): 


\section{Thermochemical half-lives of compounds $9 a$ and $9 b$}

Thermochemical half-lives were determined by irradiation a sample of compounds $9 \mathbf{a}$ and $\mathbf{9 b}$ in toluene for $1 \mathrm{~h}$ (trans $\rightarrow$ cis isomerization), and by subsequent measurement of the ratio of both species at $300 \mathrm{~K}$ with ${ }^{1} \mathrm{H}$ NMR several times over a period of five halflives (cis $\rightarrow$ trans isomerization).

\section{II.1 half-life of compound 9a}

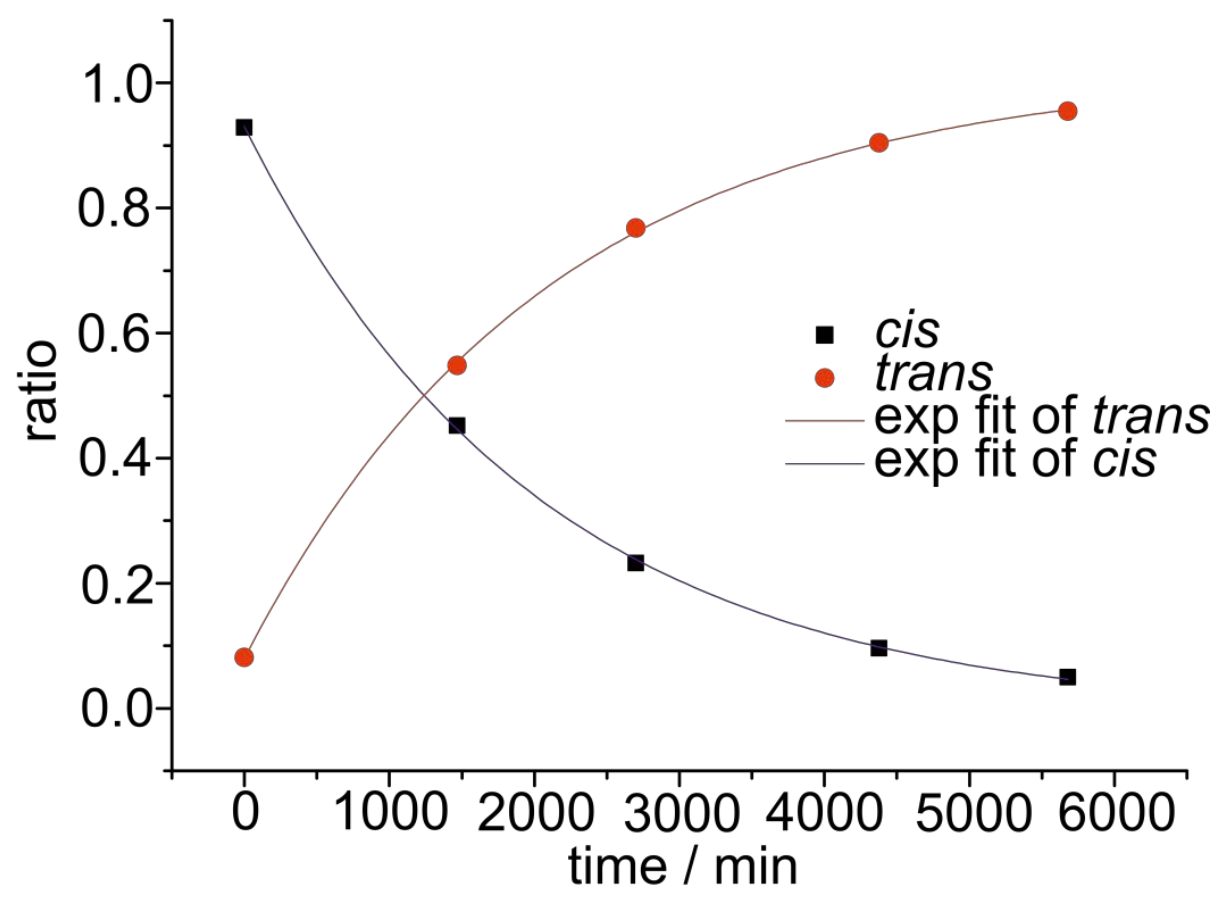

Figure S19 Ratio of cis and trans-isomer of azobenzene 9a determined with ${ }^{1} \mathrm{H}$ NMR.

Tab.1: Calculation of thermal thermochemical half-live of compound 9a.

\begin{tabular}{|c|c|}
\hline \multicolumn{2}{|c|}{ linear fit $\quad y=A e^{\frac{-x}{t_{1}}}+y_{0}$} \\
\hline linear fit of cis 9a & linear fit of trans 9a \\
\hline$A=0.94123 \pm 0.01089$ & $\mathrm{~A}=-0.93931 \pm 0.01086$ \\
$\mathrm{t}_{1}=2030.93392 \pm 60.9791$ & $\mathrm{t}_{1}=2088.1232 \pm 62.43992$ \\
$\mathrm{y}_{0}=0.01101 \pm 0.0095$ & $\mathrm{y}_{0}=1.01913 \pm 0.01002$ \\
\hline $\mathrm{k}=4.923843 * 10^{-4} \mathrm{~mol} / \mathrm{min}$ & $\mathrm{k}=4.788989 * 10^{-4} \mathrm{~mol} / \mathrm{min}$ \\
\hline $\mathrm{t}_{1 / 2}=1408 \mathrm{~min}=23.5 \mathrm{~h}$ & $\mathrm{t}_{1 / 2}=1447 \mathrm{~min}=24.1 \mathrm{~h}$ \\
\hline \multicolumn{2}{|c|}{$\mathrm{t}_{1 / 2}=1427 \mathrm{~min}=23.8 \mathrm{~h}$} \\
\hline
\end{tabular}




\section{II.2 half-life of compound 9b}

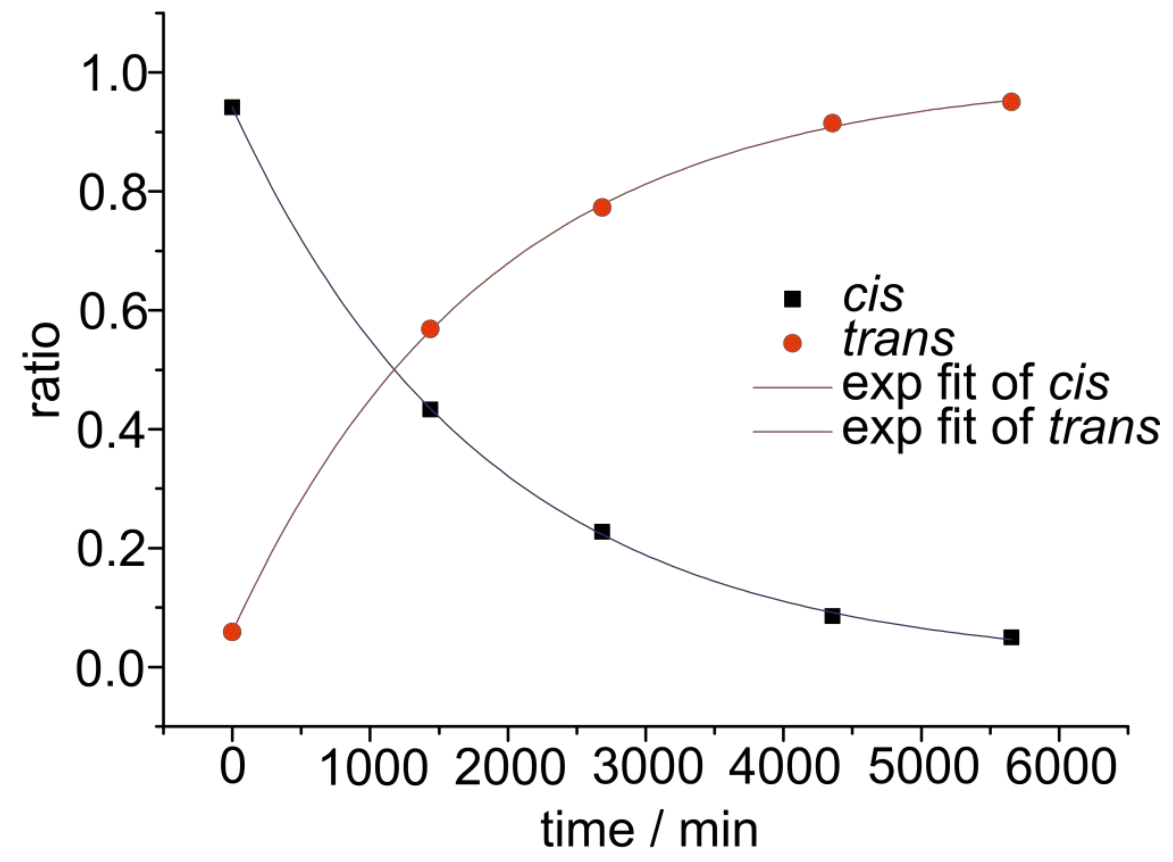

Figure S20 Ratio of cis and trans-isomer of azobenzene $\mathbf{9 b}$ determined with ${ }^{1} \mathrm{H}$ NMR.

Tab.2: Calculation of thermal thermochemical half-live of compound 9a.

\begin{tabular}{|c|c|}
\hline \multicolumn{2}{|c|}{ linear fit $\quad y=A e^{\frac{-x}{t_{1}}}+y_{0}$} \\
\hline linear fit of cis 9b & linear fit of trans 9b \\
\hline $\begin{array}{c}A=0.93951 \pm 0.00912 \\
\mathrm{t}_{1}=1854.79606 \pm 47.34129 \\
\mathrm{y}_{0}=0.00176 \pm 0.00791\end{array}$ & $\begin{array}{c}\mathrm{A}=-0.93896 \pm 0.0093 \\
\mathrm{t}_{1}=1849.40284 \pm 48.18545 \\
\mathrm{y}_{0}=0.99758 \pm 0.00805\end{array}$ \\
\hline $\mathrm{k}=5.391428317^{*} 10^{-4} \mathrm{~mol} / \mathrm{min}$ & $\mathrm{k}=5.407150775^{\star} 10^{-4} \mathrm{~mol} / \mathrm{min}$ \\
\hline $\mathrm{t}_{1 / 2}=1286 \mathrm{~min}=21.4 \mathrm{~h}$ & $\mathrm{t}_{1 / 2}=1282 \mathrm{~min}=21.4 \mathrm{~h}$ \\
\hline \multicolumn{2}{|c|}{$\mathrm{t}_{1 / 2}=1284 \mathrm{~min}=21.4 \mathrm{~h}$} \\
\hline
\end{tabular}




\section{III.1 UV-vis spectrum of 9a}

UV spectra of the pure trans isomer and of the photostationary state at $365 \mathrm{~nm}$ ( 95\% cis) of the "muscle" compound 9a were measured.

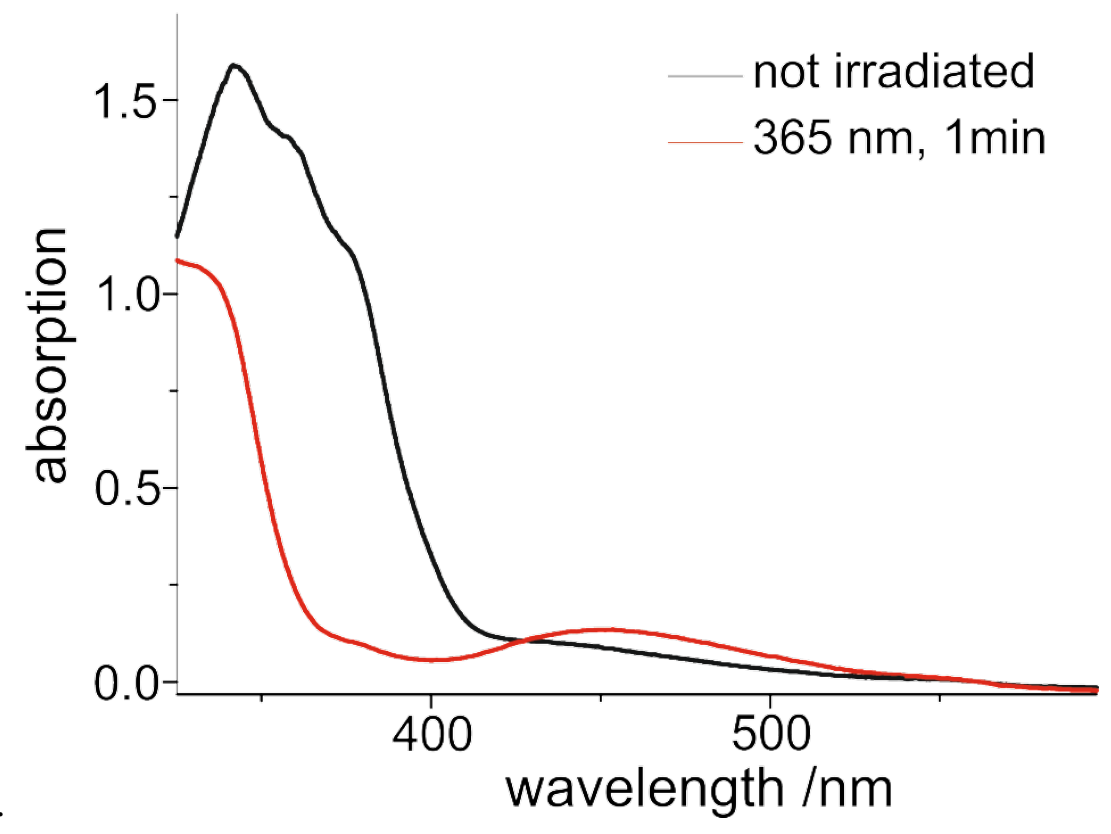

Figure S21 UV spectra of compound 9a, black curve: pure trans isomer, red curve: photostationary equilibrium at $365 \mathrm{~nm}(\sim 95 \%$ cis $)$, 


\section{III.1 Photostability of compound 9a and 9b}

The photostabilities of our compunds 9a and $\mathbf{9 b}$ were investigated by UV spectroscopy. A solution of the azobenzene in toluene was irradiated alternately with $365 \mathrm{~nm}$ and $440 \mathrm{~nm}$ for $1 \mathrm{~min}$ at every period, and after every switching process a UV spectrum was measured. The compound shows no decay or fatigue.

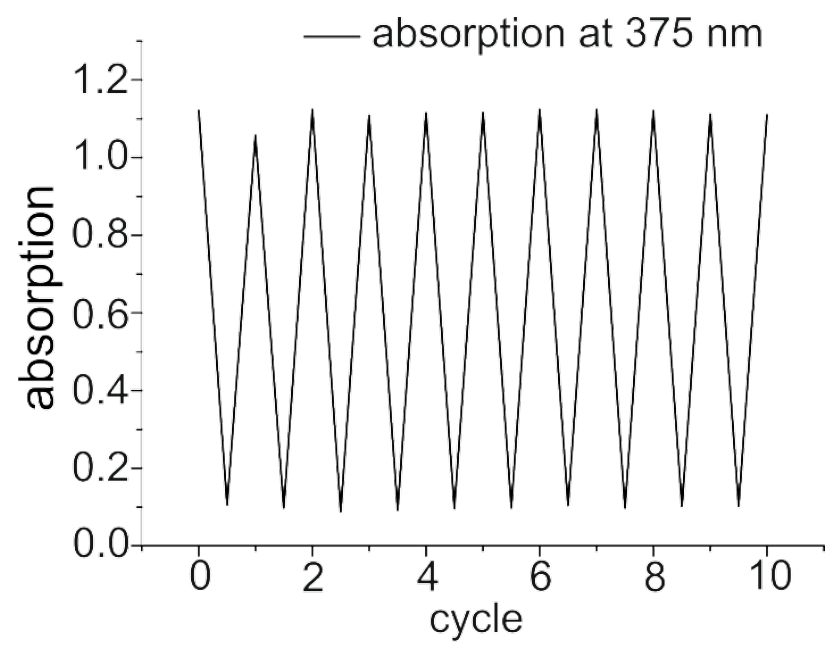

Figure S22 Photostability of compound 9a, UV spectra were measured after alternating irradiation with $365 \mathrm{~nm}$ and $440 \mathrm{~nm}$.

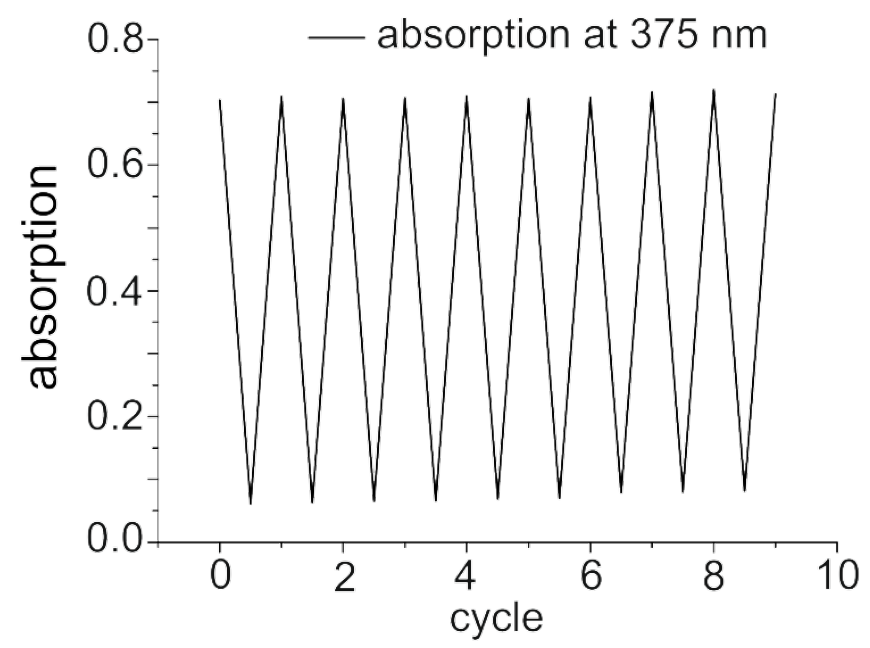

Figure S23 Photostability of compound 9b, UV spectra were measured after alternating irradiation with $365 \mathrm{~nm}$ and $440 \mathrm{~nm}$. 